\title{
INVENTÁRIO DE MOVIMENTOS DE MASSA EM ARROIO DO PADRE/RS
}

\author{
Cláudia Werner Flach ${ }^{(a)}$, Maurício Meurer ${ }^{(b)}$ \\ (a) Programa de Pós Graduação em Geografia, Universidade Federal de Pelotas, cwflach@ gmail.com \\ (b) Programa de Pós Graduação em Geografia, Universidade Federal de Pelotas, mauriciomeurer@ yahoo.com.br
}

\section{Eixo: GEOGRAFIA FÍSICA E DESASTRES NATURAIS}

\begin{abstract}
Resumo
Nos últimos 21 anos, o município de Arroio do Padre/RS foi atingido por 6 ocorrências de desastres naturais. Do total de ocorrências, 3 registros são de enxurradas. A enxurrada de 15 de novembro de 2010 foi responsável por grandes transtornos, com danos em lavouras e na infraestrutura e com o desencadeamento de movimentos de massa. Este trabalho visa organizar um inventário dos movimentos de massa ocorridos em Arroio do Padre, através da identificação e caracterização desses processos. Foram inventariados 4 movimentos de massa, sendo: dois fluxos de detritos (inativos adormecidos), um fluxo de detritos (inativo estabilizado) e um processo de queda de blocos (ativo).
\end{abstract}

Palavras chave: enxurrada; inventário; movimento de massa.

\section{Introdução}

A ocorrência de desastres naturais no Brasil é bastante frequente, entretanto, o aumento da ocupação de áreas por atividades antrópicas, associadas a falta de manejo e conservação dos solos , é responsável pelo desencadeamento de diversos problemas ambientais (GUERRA et al., 2007). Nesse cenário, as enchentes e instabilizações em encostas são consideradas, pelo meio técnico nacional, como os principais riscos físicos no país (FARAH, 2003).

Tendo em vista que as encostas têm papel fundamental no desenvolvimento de movimentos de massa, podem ser elencados 3 fatores que condicionam a estabilidade das encostas em seu estado natural: a geometria (inclinação, declividade, amplitude e perfil); a geologia (tipos e origens dos solos e rochas); e o ambiente fisiográfico em que se insere (clima, cobertura vegetal, drenagens naturais). Qualquer alteração nesses fatores pode implicar na instabilização das encostas. As ações humanas para a implantação da agricultura, pecuária, mineração e urbanização podem alterar as características originais das encostas através da retirada da vegetação, movimentações de terra, alteração do regime natural de escoamento e infiltração das águas pluviais, introdução de novas fontes de águas e deposição de material (FARAH, 2003; OLIVEIRA, 2010). 
Os movimentos de massa são constituídos por movimentos de solo, rocha ou vegetação ao longo da vertente, através da ação direta da gravidade, entretanto, "a contribuição de outro meio, como água ou gelo se dá pela redução da resistência dos materiais de vertente e/ou pela indução do comportamento plástico e fluido dos solos" (TOMINAGA, 2009, p.27). Os movimentos de massa envolvem "todo e qualquer movimento coletivo de materiais terrosos e/ou rochosos, independentemente da diversidade de processos, causas, velocidades, formas e demais características" (CASTRO, 2008), sendo "responsáveis pela mobilização de partículas, sedimentos, solo ou rocha pela encosta abaixo" (OLIVEIRA, 2010, p.25).

Os fatores condicionantes dos movimentos de massa podem ser naturais, em função das características dos solos e rochas, relevo, vegetação, clima, nível do lençol freático e gravidade, ou induzidos, através de interferências antrópicas no ambiente (OLIVEIRA, 2010). De acordo com Varnes (1978), os movimentos de massa ocorrem sob influência geológica, topográfica e climática, sendo rara a ocorrência de um evento com apenas um desses condicionantes. Fernandes et al. (2001) destacam ainda a atuação dos condicionantes geomorfológicos, pedológicos e antrópicos, elencando que os movimentos de massa ocorrem devido a interação de diversos fatores. Para Bigarella e Passos (2003), as condições para o desenvolvimento dos movimentos de massa dependem principalmente da estrutura geológica, da declividade da vertente, do regime de chuvas, da perda de vegetação, da atividade antrópica, da existência de espessos mantos intempéricos e da presença de faixas impermeáveis.

Os condicionantes geológicos englobam as características lito-estruturais e tectônicas, a composição física e química dos tipos de rochas e as propriedades mecânicas (FERNANDES, et al., 2001; PINTO et al., 2013). Os padrões de diáclases e fraturas e a presença de planos de descontinuidade influenciam no intemperismo, e consequentemente na movimentação de material nas encostas (BIGARELLA; PASSOS, 2003). Com relação às falhas e fraturas, cabe salientar que estas atuam como caminhos preferenciais de alteração do material de origem (FERNANDES; AMARAL, 1998). Quando os movimentos de massa ocorrem em áreas com regolito mais espesso, há significativa mobilização de material alterado, já em áreas com regolito pouco espesso, o material mobilizado constitui-se principalmente de blocos de rochas (BIGARELLA; PASSOS, 2003).

Os condicionantes geomorfológicos levam em consideração as relações entre a forma e a hidrologia das encostas, englobando parâmetros relacionados a declividade, forma da encosta, área de contribuição, orientação das vertentes, espessura do solo, comprimento da encosta, assimetria/simetria dos vales e elevação (FERNANDES, et al., 2001). Ou seja, os movimentos de massa são influenciados principalmente, pela morfologia da vertente, sendo a altura da vertente e inclinação, fatores importantes a serem considerados (BIGARELLA; PASSOS, 2003). 
Com relação aos condicionantes climáticos, a pluviosidade é um dos fatores de maior destaque, uma vez que os índices pluviométricos podem provocar a saturação do solo ou rocha, reduzindo a resistência à desagregação e influenciando na perda de estabilidade das encostas. Desta forma, altas pluviosidades associadas a vertentes íngremes, representam um dos principais fatores desencadeantes de movimentos de massa (PINTO et al., 2013).

Os condicionantes pedológicos exercem influência e sofrem ação dos fatores erosivos devido às diferenças de textura, estrutura, permeabilidade e densidade. As propriedades dos solos superficiais e subsuperficiais, bem como a composição litológica subjacente interferem no desencadeamento de movimentos de massa, enquanto fator desencadeante e enquanto o próprio material envolvido (PINTO et al., 2013). Outro destaque se dá ao regolito, que pode conter descontinuidades e "feições estruturais relíquias do embasamento rochoso" (FERNANDES; AMARAL, 1998, p.156), e em função da condutividade e das descontinuidades hidráulicas, "atua como um dreno para os horizontes mais superficiais" (FERNANDES; AMARAL, 1998, p.156).

Alguns autores destacam também a vegetação como fator condicionante, na medida em que a presença da cobertura vegetal mantem o equilíbrio das vertentes (PINTO et al., 2013), controlando a escoamento superficial e a infiltração da água (BIGARELLA; PASSOS, 2003). A ação antrópica, enquanto fator condicionante ao desencadeamento de movimentos de massa, é reconhecida pelos processos de uso e ocupação da terra, que influenciam na dinâmica natural das encostas através de desmatamentos, cortes nos terrenos, aterros para construção, retilinização de canais fluviais, dentre inúmeras outras atividades antrópicas (PINTO et al., 2013).

As informações sobre os movimentos de massa podem compor um inventário, permitindo o acompanhamento e o estudo das áreas de interesse, ou seja, os inventários constituem-se como fontes de informação para a compreensão dos processos nas encostas, bem como as características geotécnicas dos movimentos de massa. Nesse sentido, é fundamental que um inventário contenha o maior detalhamento possível com relação aos processos ocorridos, incluindo informações de geologia, geomorfologia, hidrologia, mecânica de solos e rochas, além de informações referentes a localização, classificação, volume, distância percorrida, estado da atividade e data de ocorrência de cada movimento de massa (FELL et al., 2008).

Os dados utilizados para a preparação do inventário podem ser compostos por informações históricas sobre deslizamentos ou por interpretação de fotografias aéreas e posterior checagem de campo (BAUZYS, 2012). Para Fell et al. (2008), duas premissas devem ser consideradas na identificação de áreas suscetíveis a movimentos de massa: o passado é guia para o futuro, uma vez que nas áreas onde já ocorreram 
deslizamentos é possível o desencadeamento de novos processos; áreas com topografia, geologia e geomorfologia similar com áreas onde que já tiveram deslizamentos podem ser afetadas.

Nesse sentido, o objetivo do presente trabalho consiste na organização do inventário de movimentos de massa ocorridos em Arroio do Padre, através da identificação e caracterização desses processos.

\section{2. Área de Estudo}

Na região sul do Rio Grande do Sul, o município de Arroio do Padre tornou-se um exemplo emblemático na questão dos desastres naturais, com 6 registros, sendo 2 de seca e estiagem, 3 de enxurrada e 1 de granizo (entre 1991 a 2012) (CEPED, 2013). Destaca-se que em um período de três anos, ocorreram 3 episódios pluviométricos de grande intensidade: as chuvas de 28 - 29 de janeiro de 2009; as chuvas de 15 de novembro de 2010; e as chuvas de 09 - 11 de março de 2011. Nestes dois últimos eventos a Prefeitura Municipal de Arroio do Padre decretou situação de emergência (MEURER; FLACH, 2015; MEURER; MARTINS, 2013).

A enxurrada de 15 de novembro de 2010 trouxe grandes transtornos para a população e para o município, com perdas econômicas na ordem de R \$ 7 milhões. Essas perdas foram resultantes de danos em lavouras e na infraestrutura, atingindo residências (sendo necessária a remoção e realocação de famílias que residiam em área de risco), estradas de acesso e pontes. Foram registrados muitos impactos ao meio ambiente, através da mobilização de material sedimentar (processos erosivos e movimentos de massa) e de alterações geomorfológicas sobre as vertentes e na rede de drenagem (MEURER; FLACH, 2015; MEURER; MARTINS, 2013).

Arroio do Padre (Figura 1) é um município com 124,27 $\mathrm{Km}^{2}$ e população de 2.730 habitantes, com predomínio da população rural (2.276 habitantes), conforme o Censo Demográfico do IBGE de 2010.

De acordo com as cartas geológicas do Projeto Levantamentos Geológicos Básicos do Brasil (escala 1:250.000) (CPRM, 2000), o município de Arroio do Padre assenta-se sobre duas suítes intrusivas: a suíte

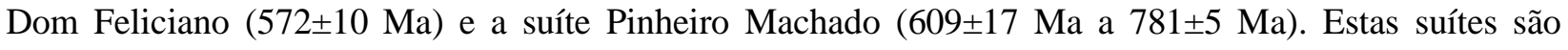
divididas em três unidades lito-estratigráficas: $\mathrm{N} \gamma 2 \mathrm{a}$ - presença de granitos róseos a cinza róseos, homogêneos, de granulação média, com isótropos levemente orientados, mormente nas bordas; $\mathrm{N} \gamma 2 \mathrm{~b}$ presença de granitos róseos a róseo avermelhados, grosseiros, porfiríticos, com foliação nas bordas; e $\mathrm{N} \gamma 1 \mathrm{a}$ - presença de milonito gnaisses e gnaisses migmáticos, incluindo restos de supracrustais e veios pegmatóides. 


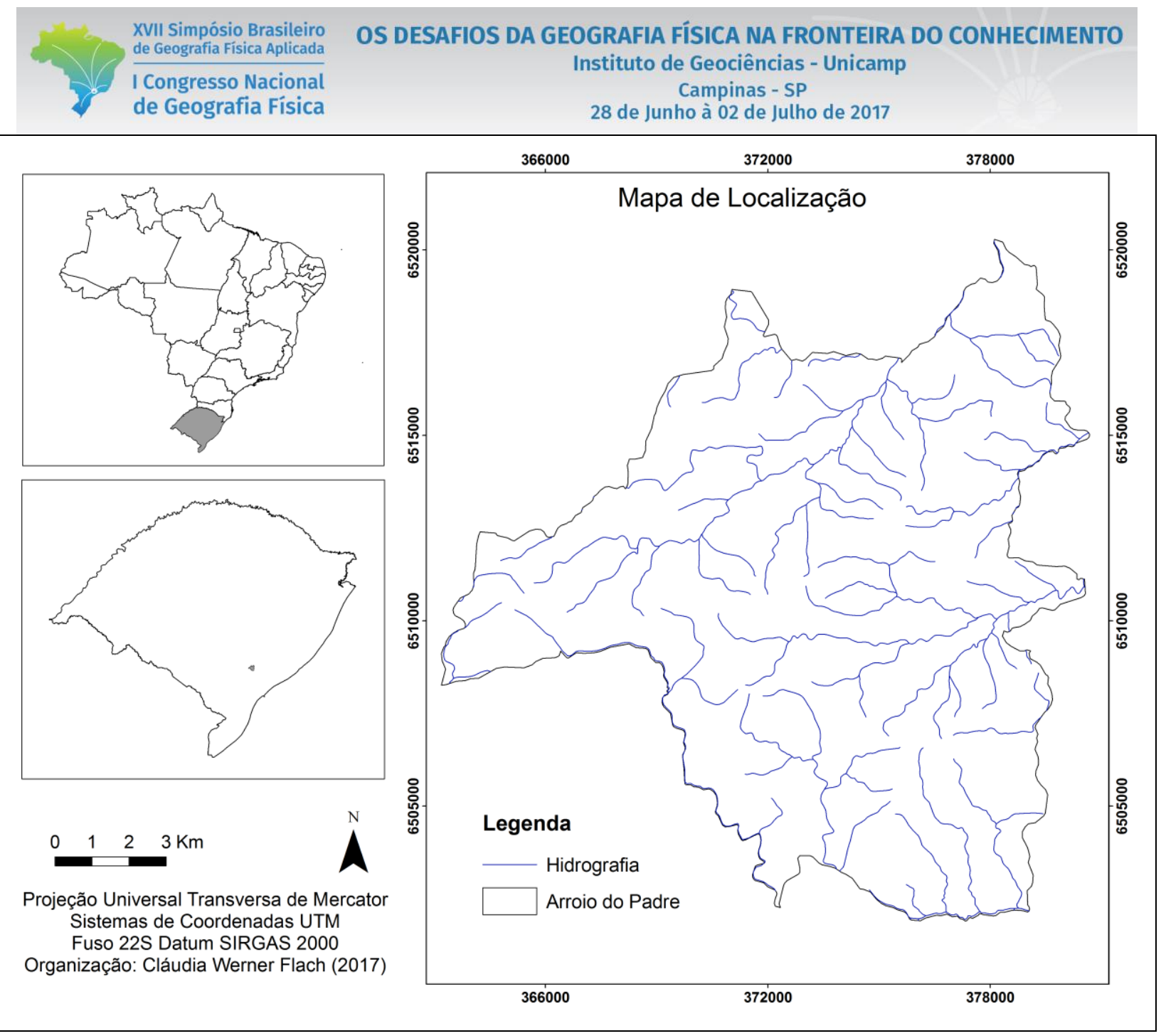

Figura 1: Mapa de localização da área de estudo.

Fonte: autores (2017).

Com relação a pedologia, o Mapa de Solos de Pelotas (escala 1:100.000) (CUNHA, 1996) permite identificar quatro classes pedológicas no município: Associação de Neossolo Litólico e Argissolo Bruno Acinzentado com presença de afloramentos rochosos; Associação de Argissolo Bruno Acinzentado e Neossolo Litólico com presença de afloramentos rochosos; Associação de Argissolo Bruno Acinzentado e Neossolo Litólico; e Argissolo Vermelho Amarelo.

Através do Mapa Geomorfológico de Arroio do Padre (escala 1:50.000) (MEURER, 2013), verifica-se que o município se encontra na transição entre o domínio morfoestrutural Embasamentos em Estilos Complexos e o domínio dos Depósitos Sedimentares, que dão origem às regiões geomorfológicas do Planalto Sul Riograndense e da Planície Continental. Essas regiões estão subdivididas em três unidades geomorfológicas: Planalto Residual Canguçu - Caçapava do Sul (tem como embasamento associações de rochas graníticas-gnáissicas; as áreas elevadas formam um conjunto de cristas alongadas, alinhadas preferencialmente nas direções W-E e SW-NE); Planalto Rebaixado Marginal (assenta-se sobre o 
embasamento formado por associações de rochas graníticas-gnáissicas e apresenta áreas de transição entre os principais divisores de águas e os vales associados aos grandes eixos de drenagem); e a Planície Alúvio Coluvionar (áreas receptoras de material sedimentar, caracterizadas como modelados de acumulação de sedimentos e subdivididas em Modelado de Acumulação Coluvial ou de Enxurrada e Modelado de Acumulação em Planície Fluvial) (MEURER, 2013).

A hipsometria da área de estudo varia entre 40 e $341 \mathrm{~m}$. Com relação a declividade, há o predomínio de áreas com declividade até 6\% (39,4\% da área), entretanto é possível identificar áreas bastante expressivas de declividade mais acentuada, como na parte Norte do município, ao longo das cristas que se comportam como divisores d'água para a Bacia Hidrográfica do Arroio Pimenta, e junto às altitudes mais elevadas (FLACH, 2017).

Com relação às coberturas e usos da terra em Arroio do Padre, o município ainda apresenta predomínio de cobertura vegetal $(53,8 \%)$, com destaque para as áreas florestais (36\%) e para as áreas campestres (17\%). Já os usos da terra ocorrem em $46,1 \%$ da área, sendo representativas as culturas temporárias (26\%), as pastagens $(10,8 \%)$ e as áreas com silvicultura $(9,1 \%)$ (FLACH, 2017).

\section{Material e Métodos}

Para coletar informações sobre os movimentos de massa ocorridos em Arroio do Padre, percorreu-se o município, em especial as áreas de declividade acentuada, a fim de registrar a ocorrência de movimentos de massa. Após essa identificação, foi possível caracterizar individualmente os movimentos de massa. Em estudo realizado anteriormente, haviam sido identificadas 2 ocorrências de movimentos de massa na Bacia Hidrográfica do Arroio Pimenta. O trabalho de campo teve como objetivos: localizar as cicatrizes dos movimentos de massa anteriormente identificados, para a caracterização dos mesmos; procurar áreas onde poderiam ter ocorrido outros processos; obter informações para o inventário; e obter registros fotográficos.

Para a caracterização dos movimentos de massa, foram coletadas informações referentes a tipo e características do solo, declividade, orientação da vertente, cobertura e uso da terra, presença ou não de surgência de água à superfície. Levando-se em consideração a classificação do WP/WLI (1993), os movimentos de massa foram classificados quanto ao estado de atividade: ativo (quando atualmente encontra-se em movimento), suspenso (quando esteve em atividade durante os últimos 12 meses, porém não se encontra ativo atualmente), reativado (quando um movimento de massa inativo passou a ser ativo) e inativo (quando não mudou nos últimos 12 meses, podendo ser subdividido em adormecido, abandonado, estabilizado e relíquia (WP/WLI, 1993). 

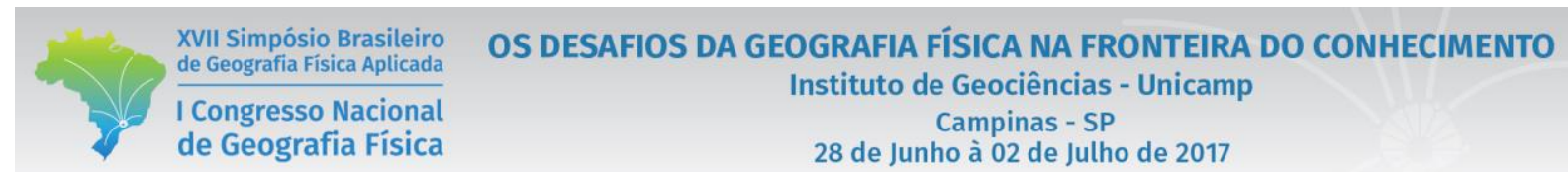

Após a realização do campo e do inventário dos movimentos de massa ocorridos em Arroio do Padre, as ocorrências foram mapeadas sobre a base cartográfica do município, através do software ArcGIS 9.3.

\section{Resultados e Discussões}

\subsection{Inventário dos Movimentos de Massa}

Conforme mencionado anteriormente, em Arroio do Padre ocorrem áreas elevadas que formam um conjunto de cristas alongadas, alinhadas preferencialmente nas direções W-E e SW-NE. É ao longo da crista de menor continuidade lateral, situada na Bacia Hidrográfica do Arroio Pimenta (BHAP), e com vertentes bastante íngremes que foram localizadas as quatro ocorrências de movimentos de massa (Figura 2). Deve-se ressaltar que todos os movimentos de massa identificados foram desencadeados durante a enxurrada de 15 de novembro de 2010 e atualmente apenas um encontra-se ativo.

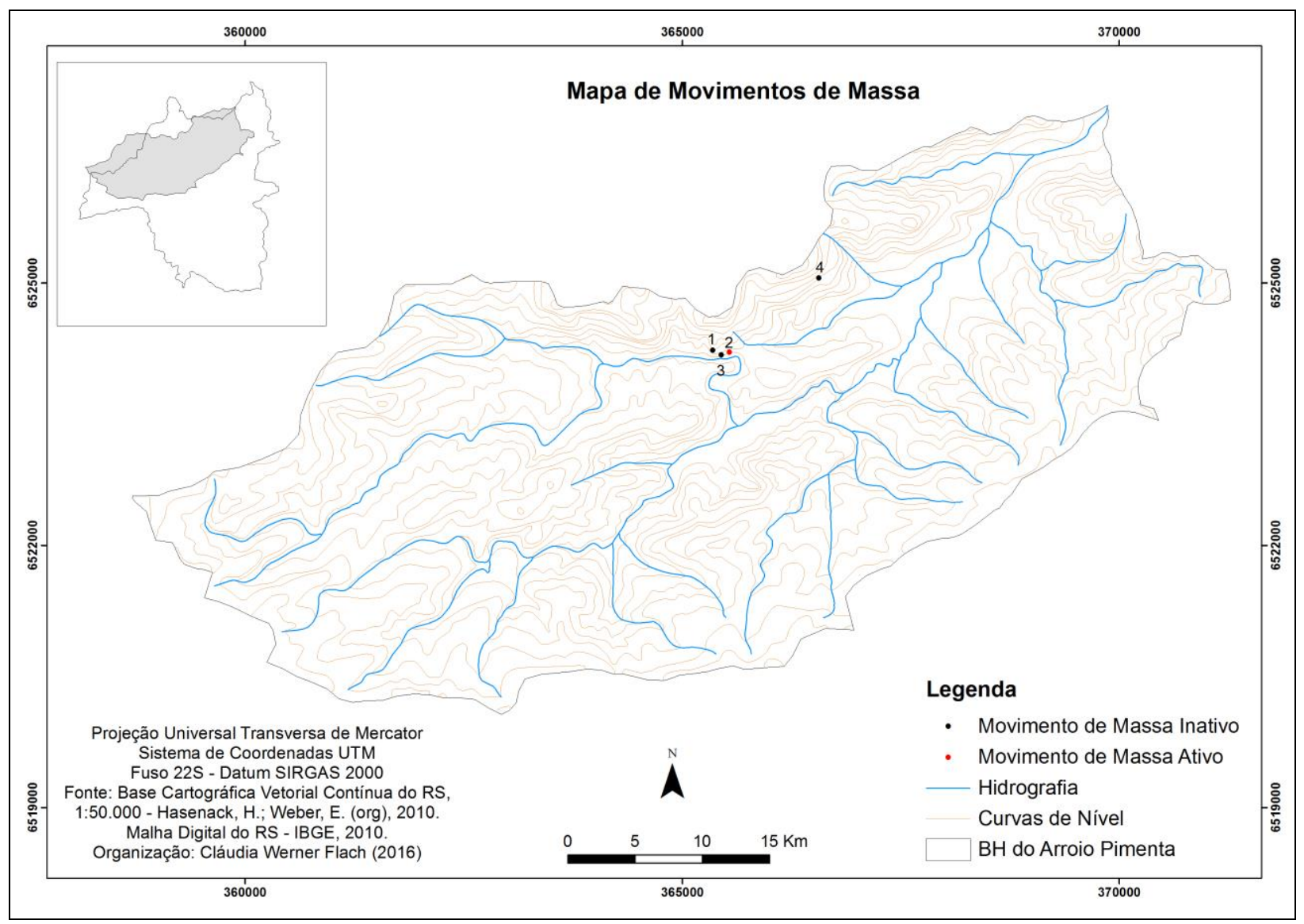

Figura 2: Mapa dos Movimentos de Massa inventariados na Bacia do Arroio Pimenta, em Arroio do Padre. Fonte: autores (2016).

O Movimento de Massa 1 (MM1) (Figura 3), localizado na BHAP (UTM 365.351m, 6.524.228m), ocorreu em setor de declividade acentuada (39,07\%), em vertente orientada a Sul. Apesar de ser 
considerado como um movimento de massa inativo (do tipo adormecido), a cicatriz ainda apresenta o plano de ruptura bem marcado na superfície, que se destaca ainda mais devido a presença pouco significativa de vegetação. Entretanto, nas adjacências da cicatriz, ocorre vegetação campestre. O MM1 foi classificado como fluxo de detritos, associado à ocorrência de rolamento de blocos, em função da mobilização de material composto por areia, grânulos, blocos e matacões. A partir das dimensões da cicatriz, estima-se que o material mobilizado tenha sido aproximadamente $30 \mathrm{~m}^{3}$. Sobre a cicatriz encontram-se dois matacões, sendo um deles com dimensões maiores $(1,69 \mathrm{~m}$ de comprimento e $0,97 \mathrm{~m}$ de altura) e um com dimensões bem menores $(0,34 \mathrm{~m}$ de comprimento e $0,27 \mathrm{~m}$ de altura). Estes matacões encontram-se temporariamente estabilizados, porém em decorrência de eventos extremos futuros, estes matacões podem vir a se desprender e rolar pela vertente em direção à estrada. O perfil do solo apresenta contato lítico dentro de $50 \mathrm{~cm}$ da superfície, revelando a presença pouco significativa de matéria orgânica, presença de grânulos e resquícios de rocha intemperizada, além de pouca coesão. A concentração do escoamento se faz visível através da formação de canais preferenciais, sendo que alguns desses sulcos apresentam mais de $20 \mathrm{~cm}$ de profundidade.

O Movimento de Massa 2 (MM2) (Figura 3), também localizado na Bacia Hidrográfica do Arroio Pimenta (UTM 365.545m, 6.524.205m) situa-se em vertente orientada a Sul e encontra-se ativo atualmente. O MM2 foi classificado como queda de blocos, devido à vertente escarpada de aproximadamente $3 \mathrm{~m}$ de altura, fornecedora do material mobilizado. Essa vertente escarpada é composta por rocha intemperizada e com fraturas e descontinuidades em diferentes orientações, além de ser concentradora do fluxo. Fundamental para o desencadeamento dos movimentos de massa, a estrutura da rocha diversas vezes está orientada no sentido do declive, atuando como um fator agravante. Parte do material removido da vertente escarpada por processos erosivos e queda de blocos resultou na formação de depósito de tálus, composto predominantemente por grânulos, seixos e blocos, em uma área com aproximadamente $5 \mathrm{~m}$ de comprimento. Esse material encontra-se acumulado na base da vertente escarpada, sob a forma de uma superfície inclinada. Sobre essa área, cresce vegetação campestre.

O Movimento de Massa 3 (MM3) (Figura 3) foi identificado em trabalho anterior, e desencadeou-se na parte superior de uma área de extração de material de empréstimo, próximo a habitações (UTM 365.447, 6.524.177). Devido a instabilidade da encosta, o local foi considerado como área de risco, e as famílias que moravam próximas a esta área foram removidas. Atualmente, a área encontra-se completamente descaracterizada e recoberta por vegetação campestre. Tendo em vista as condições encontradas no trabalho de campo, esse movimento de massa foi classificado como inativo, do tipo adormecido. O perfil do solo indica a presença significativa de material intemperizado e pouco coeso. Outro aspecto a ser considerado é a presença de áreas descobertas, com solo exposto e rocha nua. Verifica-se nessa área, que 
os cortes realizados na encosta potencializaram a instabilização da vertente, desencadeando o fluxo de detritos.

O Movimento de Massa 4 (MM4) (Figura 3), assim como todos os demais, está situado na BHAP. Esse movimento de massa ocorreu nos fundos de uma residência, em uma área de vertente escarpada. A concentração do fluxo permite a surgência de água à superfície, na base da vertente, dando origem a um poço (cacimba) destinado ao abastecimento da família. Durante a enxurrada de 15 de novembro de 2010 este poço foi entulhado com material proveniente de um movimento de massa, tendo que ser posteriormente reconstruído. A disponibilidade de água muito próxima à superfície proporciona o escoamento superficial constante. Destaca-se que essa presença do lençol freático muito próxima à superfície atua como um fator agravante aos processos erosivos, uma vez que ocorre a rápida saturação do solo em eventos pluviométricos intensos. A área onde o MM4 foi desencadeado apresenta a estrutura da rocha orientada no sentido do declive. Com relação a vegetação, sobre a vertente escarpada ocorre campo sujo, com plantas de pequeno porte. Após o desencadeamento do fluxo de detritos, foram realizadas intervenções na vertente escarpada, o que permite classificá-lo, quanto ao seu estado de atividade, como inativo estabilizado.

Além das áreas onde ocorreram movimentos de massa, durante o campo foram identificadas outras áreas com potencial para o desencadeamento de movimentos de massa ao longo da crista alongada menor na Bacia Hidrográfica do Arroio Pimenta. Foram realizados perfis de solo que permitiram verificar que ao longo dessa crista, os solos tendem a ser mais rasos e compostos por material intemperizado, com predomínio de grânulos pouco coesos. A vegetação mais exuberante dessas áreas corresponde a cobertura campestre, sendo frequentes também as áreas descobertas. Tendo em vista que essas áreas encontram-se orientadas ao Sul, a presença da umidade é um fator importante para o intemperismo químico, que tende a ser mais acentuado. Entretanto, a presença de declividades acentuadas favorece os processos erosivos e a remoção da camada superficial do solo. A presença de blocos e matacões arredondados também é frequente e muitos deles encontram-se instáveis em função das condições do relevo.

Existe também uma área de extração de saibro bastante suscetível a ocorrência de movimentos de massa. Essa área, atualmente abandonada, é formada por material intemperizado e instável. O escoamento, inicialmente difuso, concentra-se em pequenos canais organizados, resultando processos erosivos intensos nas vertentes instáveis, festonando as bordas dos patamares. Tendo em vista essas características, e o fato de estar descoberta, essa área é provavelmente uma importante fonte de sedimentos para a rede de drenagem. 


$\begin{aligned} & \text { XVII Simpósio Brasileiro } \\ & \text { de Geografia Fisica Aplicada }\end{aligned}$
$\begin{aligned} & \text { I Congresso Nacional } \\ & \text { de Geografia Física }\end{aligned}$

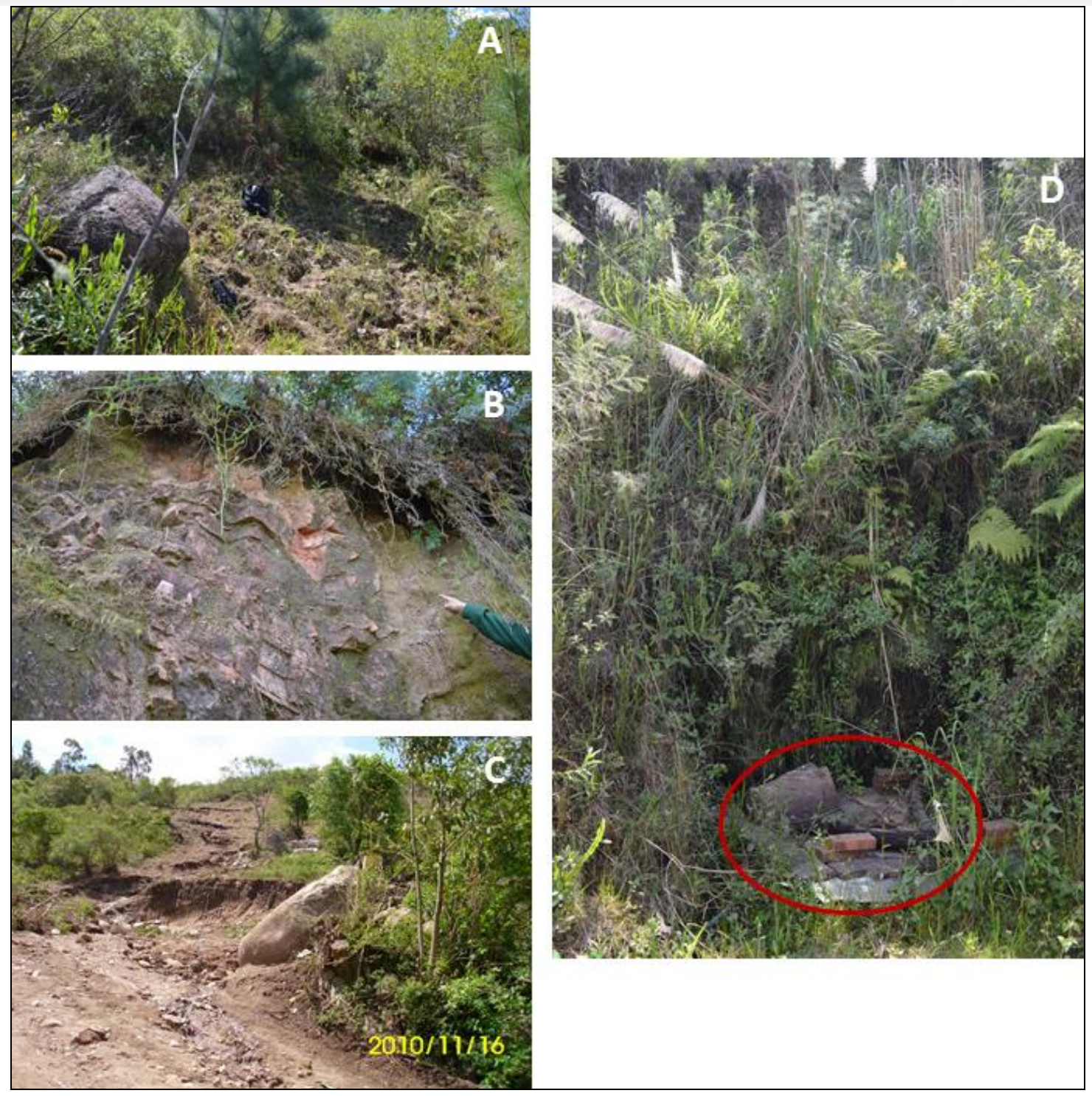

Figura 3: A) Cicatriz de movimento de massa do tipo fluxo de detritos inativo adormecido. B) Movimento de massa do tipo queda de blocos, ativo (a área mais clara na vertente escarpada indica a queda recente de material), em vertente escarpada. C) Cicatriz de movimento de massa do tipo fluxo de detritos inativo adormecido (imagem de 16/11/2010). D) Área de desencadeamento de movimento de massa (fluxo de detritos inativo estabilizado), no entorno de cacimba (em destaque).

Fonte: A) autores (2016). B) autores (2016). C) EMATER/AP (2010). D) autores (2016).

\section{Conclusões}

Até o presente momento, foram registrados apenas 4 movimentos de massa em Arroio do Padre, sendo este pequeno número de registros resultante da inexistência de monitoramento e de inventário anterior à 2015. Entretanto, a elaboração do inventário de movimentos de massa e o mapeamento dos mesmos são importantes passos para o monitoramento das ocorrências no município, bem como para a elaboração de 
trabalhos futuros. Com base no inventário de movimentos de massa ocorridos em Arroio do Padre/RS, é possível identificar que a área ao longo da crista alongada menor apresenta características favoráveis ao desencadeamento de movimentos de massa. Tendo em vista a vertente orientada a Sul, o intemperismo químico é bastante efetivo, uma vez que essas áreas são mais úmidas que as demais. Assim, o solo é constituído predominantemente por material intemperizado e pouco coeso.

Os solos pouco coesos, frequentemente úmidos, associados a declividades acentuadas $(>30 \%)$ e a precipitações intensas e prolongadas atuam como condições ideais para o desencadeamento de movimentos de massa na área de estudo. Outra característica é a vegetação campestre, que não fornece o suporte necessário para a estabilidade do solo. A presença de pastagens e culturas temporárias em áreas com declividade acentuada potencializa a instabilização das encostas, além do desencadeamento de processos erosivos.

\section{Referências}

BIGARELLA, J.J.; PASSOS, E. Estrutura e origem das paisagens tropicais e subtropicais. Florianópolis: Ed. Da UFSC, 2003 v. 3.

CASTRO, A. L. C. (Org.). Glossário de Defesa Civil. Estudos de Riscos e Medicina de Desastres. $5^{\text {a }}$ Ed. Ministério da Integração Nacional. Secretaria Nacional de Defesa Civil. Brasília: 2008

CEPED (Centro Universitário de Estudos e Pesquisas sobre Desastres). Atlas Brasileiro de Desastres Naturais: 1991 a 2012 - Rio Grande do Sul. Florianópolis: CEPED UFSC, 2013. Disponível em: http://150.162.127.14:8080 /atlas/Atlas\%20Rio\%20Grande\%20do\%20Sul\%202.pdf. Acesso em: Maio, 2016.

CPRM (Serviço Geológico do Brasil). Carta Geológica. Programa Levantamentos Geológicos Básicos do Brasil. Folha Pelotas, SH-22-Y-D. CPRM, 2000.1 mapa. Escala 1:250.000.

CUNHA, N.G. da.; Mapa de Solos de Pelotas. EMBRAPA: CPACT: Pelotas, 1996. 1 mapa. Escala $1: 100.000$.

FARAH, F. Habitações e Encostas. Coleção Habitare. São Paulo: IPT, 2003.

FELL, R. et al. Guidelines for landslide susceptibility, hazard and risk zoning for land use planning. Engineering Geology. n. 102, p. 85-98, 2008.

FERNANDES, N.F.; GUIMARÃES, R.F.; GOMES, R. A.T.; VIEIRA, B.C.; MONTGOMERY, D.R.; GREENBERG, H.Condicionantes Geomorfológicos dos Deslizamentos nas Encostas: Avaliação de Metodologias e Aplicação de Modelo de Previsão de Áreas Susceptíveis. Revista Brasileira de Geomorfologia, v.2, n.1, p.51-71, 2001.

FERNANDES, N.F.; AMARAL, C.P. Movimentos de massa: uma abordagem geológico geomorfológica. In: GUERRA, A.J.T.; CUNHA,S.B. (org.) Geomorfologia e Meio Ambiente. Rio de Janeiro: Bertrand Brasil, 1998.

FLACH, C.W. Zoneamento de Suscetibilidade a Movimentos de Massa em Arroio do Padre/RS. Dissertação de Mestrado. Pelotas: UFPel, 2017. 
GUERRA, A.J.T.; CORRÊA, A.C.B.; GIRAO, O. Encostas Urbanas como unidades de gestão e planejamento, a partir do estudo de áreas a sudoeste da cidade do Recife-PE. Revista de Geografia, Recife, v. 24, n. 3, p. 238-263, 2007.

MEURER, M. Geomorfologia e Depósitos Quaternários do município de Arroio do Padre - RS: A geomorfologia como subsídio ao planejamento e à prevenção de riscos. Relatório de Pesquisa apresentado à FAPERGS referente ao Edital 01/2011 - ARD, 2013.

MEURER, M.; MARTINS, D.P. Alterações Geomorfológicas Decorrentes da Enxurrada de Novembro de 2010 do Município de Arroio do Padre - RS. In: SIMPÓSIO BRASILEIRO DE GEOGRAFIA FÍSICA APLICADA, XV, 2013, Vitória. Anais... Vitória, 2013.

MEURER, M.; FLACH, C.W. A Geomorfologia do município de Arroio do Padre - RS e as suas relações com as Alterações Geomorfológicas da Enxurrada de 15 de novembro de 2010. Ciência e Natura, Santa Maria, v. 37 n. 3. p.311-328, 2015.

OLIVEIRA, L.M. Acidentes Geológicos Urbanos. MINEROPAR: Curitiba, 2010. Disponível em: http://www.mineropar.pr.gov.br/arquivos/File/publicacoes/Acidentes_ Geologicos_Urbanos_2010.pdf. Acesso em: Junho de 2016.

PINTO, R.C.; PASSOS, E.; CANEPARO, S.C. Considerações a respeito dos condicionantes utilizados em pesquisas envolvendo movimentos de massa. Geoingá, Maringá, v.5, n.1, p. 102-124, 2013.

TOMINAGA, L.K. Desastres Naturais: Por que ocorrem? In: TOMINAGA, L.K.; SANTORO, J.; AMARAL, R. do A. (orgs). Desastres Naturais: conhecer para prevenir. São Paulo: Instituto Geológico, 2009.

WP/WLI (Working Party/World Landslide Inventory). Multilingual Landslide Inventory. Canadá, 1993. 